\title{
PEMANFAATAN PUPUK KOMPOS JAGUNG MANIS DALAM MENINGKATKAN PRODUKSI TANAMAN JAGUNG (Zea mays L) PADA TANAH ULTISOL
}

\section{UTILIZATION OF COMPOSTED SWEET CORN STRAW FERTILIZER IN IMPROVING THE PRODUCTION OF PLANT CORN (Zea mays L.) ON AN ULTISOL SOIL}

\author{
A.Haitami, dan Wahyudi \\ ${ }^{1}$ Program Studi Agroteknologi Universitas Islam Kuantan Singingi \\ Jl. Gatot Subroto KM 7 Teluk Kuantan Telp. 0760-561655 Fax. 0760-561655 \\ Email : t.haitami@yahoo.com \\ 2 Program Studi Agroteknologi Universitas Islam Kuantan Singingi \\ Jl. Gatot Subroto KM 7 Teluk Kuantan Telp. 0760-561655 Fax. 0760-561655 \\ Email : wahyudi.uniks@gmail.co.id
}

\begin{abstract}
The aim of this research was to study influence utilization of composted corn straw fertilizer in improving the production of plant corn (Zea mays L.) on an ultisol soil. The research was conducted at Koto kari Kuantan Singingi of Riau, from Mei to July 2017. It used a Randomized Bolock Design Consisting of 5 levels of treatment and 3 groups so that there are 15 experimental units. The treatment given is: $A=$ No Treatment (control), $B=$ Compost of Corn Straw 10 tons / ha $+100 \%$ inorganic fertilizer, $C=$ Corn straw Compost 20 tons $/$ ha $+100 \%$ inorganic fertilizer, $D=$ Corn straw Compost 30 tons $/ \mathrm{Ha}+100 \%$ inorganic fertilizer, $E=100 \%$ Inorganic Fertilizer. The observed parameters were Plant height (cm), Age of female flower (HST), Harvest Age (HST), Heavy corn weight (gram), and Weight of corn without gram (gram). Data of observation result of each treatment were analyzed statistically and performed by Brightness Honest test (BNJ) at $5 \%$ level. Composting of corn straw compost has significant effect on all parameters of observation, where the best treatment is the application of 30 tons / ha of $100 \mathrm{ml}$ of corn straw compost / 100 inorganic fertilizer.
\end{abstract}

Kata Kunci : Ultisol, Jerami Jagung, Kompos.

\section{PENDAHULUAN}

Tanaman Jagung di Indonesia merupakan salah satu tanaman pangan yang penting dan mempunyai peran strategis dalam perekonomian nasional, mengingat fungsinya yang multiguna, sebagai sumber pangan, pakan, dan bahan baku industri. Kebutuhan jagung dalam negeri untuk pakan sudah mencapai 3,48 juta ton pada tahun 2004, 4,07 juta Ton pada tahun 2008 dan diprediksi meningkat menjadi 6,6 juta ton pada tahun 2010. (Departemen Pertanian 2009). Kebutuhan yang terus meningkat ini, jika tidak diimbangi dengan Peningkatan produksi yang memadai, akan menyebabkan Indonesia harus mengimpor jagung dalam jumlah besar.

Kabupaten Kuantan Singingi merupakan salah satu kabupaten yang ada di Propinsi Riau yang rawan pangan karena sebagian besar luas lahannya didominasi tanah Podzolik Merah Kuning yang termasuk kedalam ordo ultisol, sehingga dodominasi oleh komoditi perkebunan terutama perkebunan kelapa 
sawit, sehingga lahan pertanian untuk tanaman pangan sangat sempit.. Selain itu, secara umum tanah di kabupaten Kuantan Singingi berdasarkan laporan Dinas tanaman pangan tahun 2013 Kuantan Singingi didominasi oleh tanah podsolik merah kuning atau dalam klasifikasi taxonomi dikenal dengan nama ultisol. Berdasarkan penyebaran group tanah, kabupaten kuantan singingi didominasi oleh dataran tanah masam yakni sekitar 31,80 \% dan sebagian besar memiliki tingkat kemasaman tanah sekitar 4,7 -5. Menurut Hakim (2006) ultisol merupakan tanah yang memiliki $\mathrm{pH}$ dan kandungan bahan organik rendah, keracunan $\mathrm{Al}$, defisisensi $\mathrm{P}$, dan miskin unsur hara makro lainnya.

Perbaikan produktivitas dan kesuburan Ultisols dapat dilakukan dengan pengapuran, pemupukan NPK dan penambahan bahan organik yang cukup. Selama ini petani di kabupaten Kuantan Singingi hanya menggunakan pupuk buatan saja dalam memupuk tanaman pangan mereka terutama jagung, namun produksi belum juga meningkat karena penggunaan pupuk buatan terus menerus menyebabkan tanah keras, serta kekurangan bahan organik dan unsur hara. Oleh karena itu, harus ada upaya mencari sumber bahan organik yang dapat mengatasi masalah tersebut tanpa menurunkan produksi, misalnya penggunaan bahan organik yang mudah didapatkan. Berdasarkan Hasil analisis yang dilakukan di Laboratorium Central Plantations Service (2017) kandungan unsur hara pupuk kompos jerami jagung antara lain $\mathrm{pH}\left(\mathrm{H}_{2} \mathrm{O}\right) 5,45, \mathrm{~N} 0,90 \%, \mathrm{P} 1,32$ $\%$, K 1,25\%, Mg 0,29 \%, Ca 2,39 \%, Kadar Air 23,1\%.

Salah satu upaya yang dapat dilakukan agar tanaman Jagung manis dapat tumbuh subur dan berproduksi dengan baik di tanah PMK ini adalah dengan pemberian pupuk kompos limbah jagung dan pemberian pupuk berimbang. Selama ini limbah tanaman jagung kurang dimanfaatkan atau pemanfaatan tongkol jagung masih terbatas. Kebanyakan limbah tanaman jagung hanya digunakan untuk bahan tambahan makanan ternak atau sebagai pengganti kayu bakar. Limbah jagung yang diolah menjadi kompos diupayakan dapat mengembalikan bahan organik ke dalam tanah yang akan berpengaruh pada kesuburan tanah, sehingga terjadi peningkatan produksi tanaman. Pemanfaatan dengan menggunakan pupuk organik dan mengurangi pupuk Anorganik atau bahkan sama sekali tidak menggunakan pupuk kimia diharapkan dapat diperoleh manfaat jangka panjang untuk menjaga kelestarian kesuburan tanah dan meningkatkan produksi pertanian.

\section{METODE PENELITIAN}

Penelitian ini dilakukan pada tanah marginal jenis Ultisol dengan $\mathrm{pH}$ 4,5-5,5 di Desa Koto Kari Kecamatan Kuantan Tengah Kabupaten Kuantan Singingi. Analisa kompos dan tanah di lakukan di Laboratorium Central Plantations Service. Penelitian ini dilakukan selama tiga bulan dari bulan Mei sampai dengan bulan Juli 2017.

Pupuk buatan yang digunakan adalah Urea, SP36 dan $\mathrm{KCl}$. Benih jagung yang digunakan adalah varietas Pioneer. Untuk pengendalian hama dan penyakit pada tanaman digunakan curater, rhidomil, dan Leybachit. Alat-alat yang dipakai dalam penelitian ini adalah meteran, cangkul, parang, mistar, gergaji, martil, hand sprayer, gerobak sorong, timbangan, gelas ukur, ember, kamera dan alat-alat tulis.

Penelitian ini menggunakan Rancangan Acak Kelompok (RAK) yang terdiri dari 5 perlakuan dan 3 kelompok sehingga terdapat 15 satuan unit percobaan. Mengingat tanah Ultisol sangat miskin unsur hara maka takaran kompos ditingkatkan dari rekomendasi pupuk organik secara umum yaitu 20 ton/Ha dan ditambah dengan penggunaan pupuk anorganik $100 \%$ rekomendasi untuk 
mencukupi kekurangan unsur hara pada tanah Ultisol. Rekomendasi pupuk anorganik tanaman Jagung pada penelitian ini didasarkan pada rekomendasi PT. Petro Kimia Gresik menggunakan pupuk berimbang yaitu : $400 \mathrm{~kg} / \mathrm{h}$ aUrea, $150 \mathrm{~kg} / \mathrm{h}$ a SP-36 dan $75 \mathrm{~kg} / \mathrm{haKCl}$. Perlakuan yang diberikan adalah : $\mathrm{A}=$ Tanpa Perlakuan (kontrol), $\mathrm{B}=$ Kompos Jagung Manis 10 ton/ha $+100 \%$ pupuk anorganik, $\mathrm{C}=$ Kompos Jagung Manis 20 ton/ha $+100 \%$ pupuk anorganik, $\mathrm{D}=$ Kompos Jagung Manis 30 ton/ha + $100 \%$ pupuk anorganik, $E=100 \%$ Pupuk Anorganik. Parameter yang diamati adalah Tinggi tanaman (cm), Umur Muncul Bunga
Betina (HST), Umur Panen (HST), Berat jagung berkelobot (gram), dan Berat jagung tanpa kelobot (gram).

\section{HASIL DAN PEMBAHASAN}

\section{Tinggi tanaman (cm)}

Hasil pengamatan terhadap tinggi tanaman setelah dilakukan analisis sidik ragam, menunjukkan bahwa pengaruh pemberian pupuk kompos jerami jagung, memberikan pengaruh yang nyata terhadap tinggi tanaman jagung dari umur 1 bulan dan saat panen. Data rata-rata tinggi tanaman jagung disajikan pada Tabel 1.

Tabel 1. Rerata tinggi tanaman jagung terhadap perlakuan kompos jagung manis $+100 \%$ pupuk anorganik.

\begin{tabular}{lcc}
\hline \multicolumn{1}{c}{ Perlakuan } & Umur 1 bulan (cm) & Saat panen (cm) \\
\hline $\mathrm{A}=$ Tanpa perlakuan (kontrol) & $50,33 \mathrm{c}$ & $191,57 \mathrm{c}$ \\
$\mathrm{B}=10$ ton/ha $+100 \%$ pupuk & $72,40 \mathrm{bc}$ & $194,23 \mathrm{bc}$ \\
anorganik & & \\
$\mathrm{C}=20$ ton/ha $+100 \%$ pupuk & $84,00 \mathrm{ab}$ & $201,62 \mathrm{~b}$ \\
anorganik & & \\
$\mathrm{D}=30$ ton/ha $+100 \%$ pupuk & $98.89 \mathrm{a}$ & $221,93 \mathrm{a}$ \\
anorganik & & $192,50 \mathrm{c}$ \\
$\mathrm{E}=100 \%$ Pupuk Anorganik saja & $67,33 \mathrm{bc}$ & $\mathrm{KK}=1,49 \% \mathrm{NJ}=8,45$ \\
\hline
\end{tabular}

Angka - angka pada kolom dan baris yang diikuti huruf kecil yang sama tidak berbeda nyata menurut Uji Beda Nyata Jujur (BNJ) pada taraf $5 \%$.

Berdasarkan uji BNJ 5 \% bahwa dari tabel 1 terlihat bahwa perlakuan pupuk kompos jagung manis 30 ton/ha $+100 \%$ pupuk anorganik berbeda nyata dengan perlakuan lainnya, baik pada umur 1 bulan dan saat panen. Adanya perbedaan tersebut menunjukkan bahwa dengan pemberian pupuk Kompos Jagung Manis dapat menyumbangkan hara pada tanaman, sehingga mempengaruhi tinggi tanaman pada umur 1 bulan dan saat panen. Hal ini sejalan dengan pendapat Gardner et al. (1991) menjelaskan bahwa proses pertambahan tinggi tanaman terjadi karena peningkatan jumlah sel serta pembesaran ukuran sel. Hal ini seiring juga dengan pendapat Loomis \& Connor, (1992),
Peningkatan hasil terjadi sebanding dengan tingkat pemupukan pada kebanyakan tanaman yang diusahakan. Karena itu, kebutuhan global unsur hara primer yang digunakan untuk pupuk $\mathrm{N}, \mathrm{P}$ dan $\mathrm{K}$ terus meningka tuntuk memenuhi kebutuhan pangan yang terus meningkat dengan waktu.

Hasil pengamatan terhadap Umur muncul Bunga setelah dilakukan analisis sidik ragam, menunjukkan bahwa pengaruh pemberian pupuk kompos jerami jagung, memberikan pengaruh yang nyata terhadap Umur muncul bunga betina tanaman jagung. Data rata-rata Umur muncul bunga tanaman jagung disajikan pada Tabel 2. 
Tabel 2. Rerata umur muncul bunga betina tanaman jagung terhadap perlakuan kompos jagung manis $+100 \%$ pupuk anorganik.

Umur Muncul Bunga Betina (HST)

\begin{tabular}{cc}
\hline Perlakuan & Rerata \\
\hline$A=$ Tanpa perlakuan (kontrol) & $53,00 \mathrm{a}$ \\
$B=10$ ton/ha $+100 \%$ pupuk anorganik & $52,00 \mathrm{a}$ \\
$C=20$ ton/ha $+100 \%$ pupuk anorganik & $48,67 \mathrm{bc}$ \\
$D=30$ ton/ha $+100 \%$ pupuk anorganik & $46,33 \mathrm{c}$ \\
$E=100 \%$ Pupuk Anorganik saja & $51,00 \mathrm{ab}$ \\
\hline KK $=2,24 \%$ & $\mathrm{BNJ}=3,17$
\end{tabular}

Angka - angka pada kolom dan baris yang diikuti huruf kecil yang sama tidak berbeda nyata menurut Uji Beda Nyata Jujur (BNJ) pada taraf $5 \%$.

Berdasarkan uji BNJ 5 \% bahwa dari tabel 2, dapat dilihat bahwa pemberian perlakuan 30 ton/ha pupuk kompos jerami jagung + $100 \%$ pupuk anorganik berbeda nyata dengan perlakuan lainnya terhadap parameter umur berbunga. Hal ini disebabkan karena unsur hara yang diberikan melalui perlakuan memberikan respon pertumbuhan, maka mempengaruhi pertumbuhan umur muncul bunga. Hal ini sejalan dengan pendapat Saptarini et al, (1989) mengemukakan bahwa pertumbuhan suatu tanaman akan dipengaruhi oleh faktor lingkungan dan genetik. Hal ini disebabkan pada saat tanaman mengeluarkan bunga, memerlukan suhu yang tinggi dan ketersediaan air yang cukup untuk membantu penyerbukan tanaman sehingga dapat mempercepat munculnya bunga. Hal ini sesuai dengan pendapat Mapegau (2006) yang menyatakan bahwa salah satu kendala yang dapat membatasi pertumbuhan dan produksi tanaman pada lahan kering adalah ketersediaan air yang rendah karena itu diperlukan kultivar jagung yang berpotensi produksi dan mempunyai kemampuan yang tinggi tehadap cekaman air.

Hasil pengamatan terhadap Umur panen setelah dilakukan analisis sidik ragam, menunjukkan bahwa pengaruh pemberian pupuk kompos jerami jagung, memberikan pengaruh yang nyata terhadap Umur panen tanaman jagung. Data rata-rata Umur panen tanaman jagung disajikan pada Tabel 3.

Tabel 3. Rerata umur panen tanaman jagung terhadap perlakuan kompos jagung manis +100 $\%$ pupuk anorganik

\section{Umur Panen (HST)}

\begin{tabular}{lc}
\hline \multicolumn{1}{c}{ Perlakuan } & Rerata \\
\hline$A=$ Tanpa perlakuan (kontrol) & $73,67 \mathrm{a}$ \\
$\mathrm{B}=10$ ton/ha $+100 \%$ pupuk anorganik & $70,67 \mathrm{ab}$ \\
$\mathrm{C}=20$ ton/ha $+100 \%$ pupuk anorganik & $68,00 \mathrm{bc}$ \\
$\mathrm{D}=30$ ton/ha $+100 \%$ pupuk anorganik & $65,33 \mathrm{c}$ \\
$\mathrm{E}=100 \%$ Pupuk Anorganik saja & $71,33 \mathrm{ab}$ \\
\hline $\mathrm{KK}=1,72 \%$ & $\mathrm{BNJ}=3,37$ \\
\hline
\end{tabular}


Angka - angka pada kolom dan baris yang diikuti huruf kecil yang sama tidak berbeda nyata menurut Uji Beda Nyata Jujur (BNJ) pada taraf $5 \%$.

Berdasarkan uji BNJ $5 \%$ bahwa umur panen tercepat pada perlakuan 30 ton/ha + $100 \%$ pupuk Anorganik yaitu 65, 33 hari. Hal ini disebabkan oleh waktu tanam yang tepat dan sesuai dengan kriteria pertumbuhannya. Hal ini juga dipengaruhi oleh faktor -faktor iklim seperti suhu, curah hujan dan intensitas sinar matahari yang mendukung sebagai faktor -faktor pertumbuhan yang dapat mempengaruhi pertumbuhan dan produksi tanaman tersebut. Hal sesuai dengan Warisno (1998) yang menyatakan bahwa waktu tanam yang tepat merupakan salah satu usaha untuk memperkecil kegagalan panen.

Hasil pengamatan terhadap Berat jagung berkelobot/tanaman setelah dilakukan analisis sidik ragam, menunjukkan bahwa pengaruh pemberian pupuk kompos jagung manis, memberikan pengaruh yang nyata terhadap Berat jagung berkelobot/tanaman. Data rata-rata berat jagung berkelobot tanaman jagung disajikan pada Tabel 4.

Tabel 4. Rerata Berat jagung berkelobot/tanaman terhadap perlakuan kompos jagung manis + $100 \%$ pupuk anorganik

\section{Berat Jagung Berkelobot/tanaman (gram)}

\begin{tabular}{cc}
\hline Perlakuan & Rerata \\
\hline$A=$ Tanpa perlakuan (kontrol) & $142,08 \mathrm{c}$ \\
$B=10$ ton/ha $+100 \%$ pupuk anorganik & $233,00 \mathrm{ab}$ \\
$\mathrm{C}=20$ ton/ha $+100 \%$ pupuk anorganik & $255,08 \mathrm{a}$ \\
$\mathrm{D}=30$ ton/ha $+100 \%$ pupuk anorganik & $276,00 \mathrm{a}$ \\
$\mathrm{E}=100 \%$ Pupuk Anorganik saja & $194,25 \mathrm{~b}$ \\
\hline $\mathrm{KK}=7,03 \%$ & $\mathrm{BNJ}=43,64$
\end{tabular}

Angka - angka pada kolom dan baris yang diikuti huruf kecil yang sama tidak berbeda nyata menurut Uji Beda Nyata Jujur (BNJ) pada taraf $5 \%$.

Berdasarkan uji BNJ $5 \%$ bahwa dari tabel 4, dapat dilihat bahwa pemberian perlakuan 30 ton/ha pupuk kompos jagung manis + $100 \%$ pupuk anorganik berbeda nyata dengan perlakuan lainnya terhadap parameter berat jagung berkelobot/tanaman. Hal ini disebabkan bahwa kandungan unsur hara pada pupuk kompos jerami jagung dan pada pupuk anorganik yang diberikan $100 \%$ yaitu unsur hara $\mathrm{N}, \mathrm{P}, \mathrm{K}$ dapat dimanfaatkan dengan optimal pada tanaman jagung. Penelitian ini juga sejalan dengan pendapat Sintia (2011), pemberian unsur hara yang berimbang dapat meningkatkan hasil tanaman jagung. Hasil pengamatan terhadap Berat jagung tanpa kelobot/tanaman setelah dilakukan analisis sidik ragam, menunjukkan bahwa pengaruh pemberian pupuk kompos jerami jagung, memberikan pengaruh yang nyata terhadap Berat jagung tanpa kelobot/tanaman. Data rata-rata Berat jagung tanpa kelobot/tanaman jagung disajikan pada Tabel 5. 
Tabel 5. Rerata Berat jagung tanpa kelobot/tanaman terhadap perlakuan kompos jagung manis $+100 \%$ pupuk anorganik

Berat Jagung Tanpa Kelobot/tanaman (gram)

\begin{tabular}{cc}
\hline \multicolumn{1}{c}{ Perlakuan } & Rerata \\
\hline $\mathrm{A}=$ Tanpa perlakuan (kontrol) & $102,92 \mathrm{~b}$ \\
$\mathrm{~B}=10$ ton/ha $+100 \%$ pupuk anorganik & $166,91 \mathrm{a}$ \\
$\mathrm{C}=20$ ton/ha $+100 \%$ pupuk anorganik & $189,92 \mathrm{a}$ \\
$\mathrm{D}=30$ ton/ha $+100 \%$ pupuk anorganik & $197,75 \mathrm{a}$ \\
$\mathrm{E}=100 \%$ Pupuk Anorganik saja & $148,92 \mathrm{ab}$ \\
\hline $\mathrm{KK}=12,83 \%$ & $\mathrm{BNJ}=58,35$
\end{tabular}

Angka - angka pada kolom dan baris yang diikuti huruf kecil yang sama tidak berbeda nyata menurut Uji Beda Nyata Jujur (BNJ) pada taraf $5 \%$.

Berdasarkan uji BNJ 5 \% bahwa dari tabel 5 , dapat dilihat bahwa pemberian perlakuan 30 ton/ha pupuk kompos jagung manis + $100 \%$ pupuk anorganik berbeda nyata dengan perlakuan lainnya terhadap parameter berat jagung tanpa kelobot/tanaman. Hal ini diduga pada saat inilah terjadi penimbunan bahan kering dari daerah sumber ke daerah paling efektif, dan hal ini diduga berhubungan erat dengan besarnya fotosintat yang ditranslokasikan ke bagian tongkol. Semakin besar fotosintat yang ditranslokasikan ke tongkol maka semakin meningkat pula berat segar tongkol yang dihasilkan. Salisbury \& Ross (1992) menyatakan bahwa luas daun tanaman merupakan suatu faktor yang menentukan

\section{DAFTAR PUSTAKA}

Gardner, F. P. ; R. B. Pearce dan R. L. Mitchell. 1991. Fisiologi Tanaman Budidaya. Terjemahan: Herawati Susilo. UI Press, Jakarta.

Hakim, N. 2006. Pengelolaan Kesuburan Tanah Masam dengan Teknologi Pengapuran Terpadu. Padang. Andalas University Press. 204 hal. jumlah energi matahari yang dapat diserap oleh daun dan akan menentukan besarnya fotosintat yang dihasilkan.

\section{KESIMPULAN}

Berdasarkan hasil penelitian ini dapat disimpulkan bahwa pemanfaatan kompos jerami jagung dan pemberian 100 $\%$ pupuk anorganik dapat meningkatkan produksi tanaman jagung pada tanah ultisol, dimana penambahan pupuk organik dan ditambah lagi dengan penggunaan pupuk anorganik yang berimbang sangat memberikan kontribusi pada tanah ultisol dalam meningkatkan produksi tanaman jagung.

Jamilah. R.Munir, dan Fatimah. 2009. Upaya Menggantikan Pupuk Kimia Buatan dengan Kompos C. Odorata dan Guano Untuk Tanaman Jagung (Zea Mays L.) Pada Pengelolaan Tanah Marginal Secara Berkelanjutan. Laporan Penelitian Hibah Bersaing. Fakultas Pertanian UNITAS. Padang

Loomis, R.S. and Connor, D.J., 1992. Crop ecology: productivity and management in agricultural 
systems. Cambridge University Press $538 \mathrm{p}$.

Mapegau, 2006. Pengaruh Cekaman Air Terhadap Pertumbuhan da Hasil Tanaman Kedelai (Glycine max L. Merr.) Jurnal Ilmiah Pertanian Kultura 41 : 43 Fakultas Pertanian USU. Medan.

Salisbury, F.B. \& C.W. Ross. 1992. Plant Physiology. 4thEd. Wadsworth Publishing Company Bellmount, California. 681 hal.

Saptarini, N. S, N. D. E. Widayati. 1989. Membuat
Berbuah. Penebar Swadaya. Jakarta.

Sintia, M. 2011. Pengaruh Beberapa Dosis Kompos Jerami Padi dan Pupuk Nitrogen Terhadap Pertumbuhan dan Hasil Jagung Manis (Zea mays saccharata sturt.) Skripsi Dipulikasikan.

http://repository.unand.ac.id/1679 0/1/jurnal MEGI SINTIA \%2807 111024\%29.pdf (Diakses tgl 2 Agustus 2017).

Warisno. 2008. Jagung Hibrida. Kanisius. Yogyakarta. 